\title{
Primary hyperparathyroidism diagnosed after surgical ablation of a costal mass mistaken for giant-cell bone tumor: a case report
}

\author{
Lara Vera', Mara Dolcino ${ }^{1}$, Marco Mora$^{2}$, Silvia Oddo ${ }^{1}$, Marina Gualco ${ }^{2}$, Francesco Minuto ${ }^{1}$ and Massimo Giusti ${ }^{*}$
}

\begin{abstract}
Introduction: Primary hyperparathyroidism is a common endocrine disorder characterized by elevated parathyroid hormone levels, which cause continuous osteoclastic bone resorption. Giant cell tumor of bone is an expansile osteolytic tumor that contains numerous osteoclast-like giant cells. There are many similarities in the radiological and histological features of giant cell tumor of bone and brown tumor. This is a rare benign focal osteolytic process most commonly caused by hyperparathyroidism.

Case presentation: We report the unusual case of a 40-year-old Caucasian woman in which primary hyperparathyroidism was diagnosed after surgical ablation of a costal mass. The mass was suspected of being neoplastic and histopathology was compatible with a giant cell tumor of bone. On the basis of the biochemical results (including serum calcium, phosphorous and intact parathyroid hormone levels) primary hyperparathyroidism was suspected and a brown tumor secondary to refractory hyperparathyroidism was diagnosed.
\end{abstract}

Conclusions: Since giant cell tumor is a bone neoplasm that has major implications for the patient, the standard laboratory tests in patients with bone lesions are important for a correct diagnosis.

\section{Introduction}

Primitive hyperparathyroidism (PHPT) is the third most common endocrine disorder after diabetes mellitus and thyroid dysfunction [1]. The estimated incidence of cases of PHPT is $0.2 \%$ to $0.3 \%$ [2]. The diagnosis of PHPT has classically been based on the demonstration of high plasma calcium and low plasma phosphorus concentrations. In recent years, however, it has been recognized that patients with PHPT may present with plasma calcium concentrations within the normal range [3]. About $75 \%$ to $80 \%$ of cases of PHPT are diagnosed when a routine assay shows hypercalcemia in patients who are asymptomatic or during evaluation for osteoporosis. Surgical ablation is the treatment of choice for PHPT. Persistent hyperparathyroidism leads to altered osseous metabolism involving bone resorption and tissue changes that are collectively known as osteitis fibrosa cystica (OFC) [3]. Today, $<5 \%$ of patients

\footnotetext{
* Correspondence: magius@unige.it

'Department of Internal Medicine, University of Genoa, Viale Benedetto XV, 6-16132, Genoa, Italy

Full list of author information is available at the end of the article
}

display evidence of OFC [4]. Osteitis fibrosa cystica is characterized by the presence of subperiosteal resorption in the digits, skull and long bones, diffuse osteopenia, and brown tumor [5].

Brown tumor is an extremely rare osseous lesion that constitutes a focal manifestation of OFC induced by hyperparathyroidism, independently of its cause. The reported prevalence of brown tumors is $0.1 \%$, and they have been reported to occur in $4.5 \%$ of patients with PHPT and in $1.5 \%$ to $1.7 \%$ of those with secondary disease [6,7]. The disease can manifest itself at any age, but is more common among people older than 50 years, and is three times more common in women than in men [8]. Brown tumor may be the first clinical sign of hyperparathyroidism. Histologically, brown tumors are made up of mononuclear stromal cells mixed with multinucleated giant cells, among which recent hemorrhagic infiltrates and hemosiderin deposits (hence the brown color) are often found $[9,10]$. Brown tumors may appear in any of the bones [11]. However, when the same type of lesion is found in patients without PHPT, the differential diagnosis becomes more complex.

\section{Biomed Central}


Many of the radiological and histological features of brown tumor, a benign osteolytic process, are similar to those of giant cell tumor (GCT) of bone. Giant cell tumor of bone is an uncommon primary bone tumor that accounts for around 5\% of all primary bone tumors [12]. Giant cell tumor is a locally aggressive tumor characterized by a high number of multinuclear giant cells that exhibit the features of mature osteoclasts [13]. Clinically, most patients with GCT are asymptomatic or present with bone pain due to enlargement of the tumor. Malignant transformation of GCT is a rare event, occurring in less than $1 \%$ of all cases [14]. The treatment of primary GCT is essentially surgical [12]. The differential diagnosis is based on biochemical analysis.

Here, we report the case of a patient with an incidentally discovered costal mass, the diagnostic investigation of which led to an unexpected diagnosis.

\section{Case presentation}

We describe the case of a 40-year-old Caucasian woman who had first been examined at the Department of Internal Medicine of our University Hospital three years ago for a Reynaud-like disorder. Her medical history was unremarkable except for an oligomenorrhea since she was 26 years of age. A physical examination revealed a fair condition. A chest X-ray showed a peripheral lesion, approximately $8 \mathrm{~cm}$ in diameter, of the third right rib with cortical expansion; this was confirmed by a contrast tomography scan. The lesion was associated with an area of bone rarefaction of the lamina of L2. The bone mass was suspected of being a neoplastic lesion. Subsequently, ${ }^{\mathrm{m} 99} \mathrm{Tc}$ bone scintigraphy revealed a hyper-metabolic focus in the rib and in the medial condylus of the right femur, while an magnetic resonance imaging (MRI) scan showed an aneurysmal cystic bone lesion. Costal biopsy showed numerous osteoclast-like giant plurinuclear cells, without necrosis, mitoses or histological signs of malignancy; a picture compatible with GCT of bone. Six months after diagnosis, the mass was surgically removed and local curettage was performed, with excision of the right major pectoralis and part of the II, III and IV right ribs. Histology showed a neoplasm with a solid structure made up of bland mononuclear stromal cells and an osteoclast-type giant cellrich component, a picture compatible with GCT.

On gross examination, the surgical specimen consisted of a soft, well circumscribed endothoracic mass of $6 \times$ $4.5 \times 2.2 \mathrm{~cm}$, with a tan and fleshy cut surface, which conglobated two ribs (11 cm and $5.5 \mathrm{~cm}$ in length). On microscopic examination, the tumor was seen to be composed of a large number of single multinucleated giant cells diffusely distributed on a background of spindle-shaped, oval or polygonal mononuclear cells; these latter cells were characterized by abundant eosinophilic cytoplasm and oval nuclei without atypia. No aggregates of giant cells were observed. Necrosis and areas of hemorrhage were not observed. The mononuclear component displayed a low mitotic index (6/10 high-power field [HPF]) (Figure 1).

One month after surgery, during the first medical and laboratory follow-up examination, an increase in serum calcium $(3.6 \mathrm{mmol} / \mathrm{L})$ and alkaline phosphatase (ALP: $501 \mathrm{U} / \mathrm{L}$ ) levels was found. Our patient's parathyroid function was found to be elevated (parathyroid hormone $[\mathrm{PTH}]: 712 \mathrm{ng} / \mathrm{L})$. Our patient was referred for endocrine evaluation two months after surgery. Review of her medical records revealed hypercalcemia, which had been underestimated at the first examination. Her family history was negative for parathyroid and other endocrine diseases. PHPT was suspected. No cervical masses were palpable. Neck ultrasonography identified a round lesion located behind and below the right thyroid lobe and compatible with an enlarged parathyroid gland, whereas the thyroid was normal (Figure 2). $\mathrm{A}^{99} \mathrm{~m}_{\mathrm{Tc}}$-sestamibi scan revealed a hyper-functioning area in the upper right portion of the thyroid bed, which was suspected of being an underlying parathyroid adenoma (Figure 3). Cytological examination of a fine-needle aspiration biopsy of the nodular lesion was compatible with a parathyroid adenoma. Sequencing of the multiple endocrine neoplasia (MEN)-1 gene proved normal. All biochemical data observed before parathyroidectomy are reported in Table 1 and in the legend to Figure 2. A mini-invasive parathyroidectomy was scheduled. Histology confirmed the diagnosis of adenoma of the right inferior parathyroid gland. Post-operative laboratory tests showed normal levels of serum calcium $(2.3 \mathrm{mmol} / \mathrm{L})$ and PTH $(80 \mathrm{ng} /$ L). After a review of bone slices, the final diagnosis of the bone disease was a brown tumor secondary to probably long-standing underestimated PHPT. At present, one year later, our patient is free from symptoms and dual-emission X-ray absorptiometry (DXA) has shown that her bone density has improved (Table 1).

\section{Discussion}

Primitive hyperparathyroidism involves a heterogeneous group of patients with various symptoms and pathological conditions.

Brown tumor is an unusual non-neoplastic lesion resulting from abnormal bone metabolism in hyperparathyroidism and represents a reparative cellular process [15] that arises from foci of OFC, the end stage of a bone-remodeling condition. Brown tumor is mainly due to secondary hyperparathyroidism in patients with renal insufficiency, but it has also been described as an extremely rare manifestation of PHPT [11], usually resulting from PTH overproduction by adenomas [16] or 


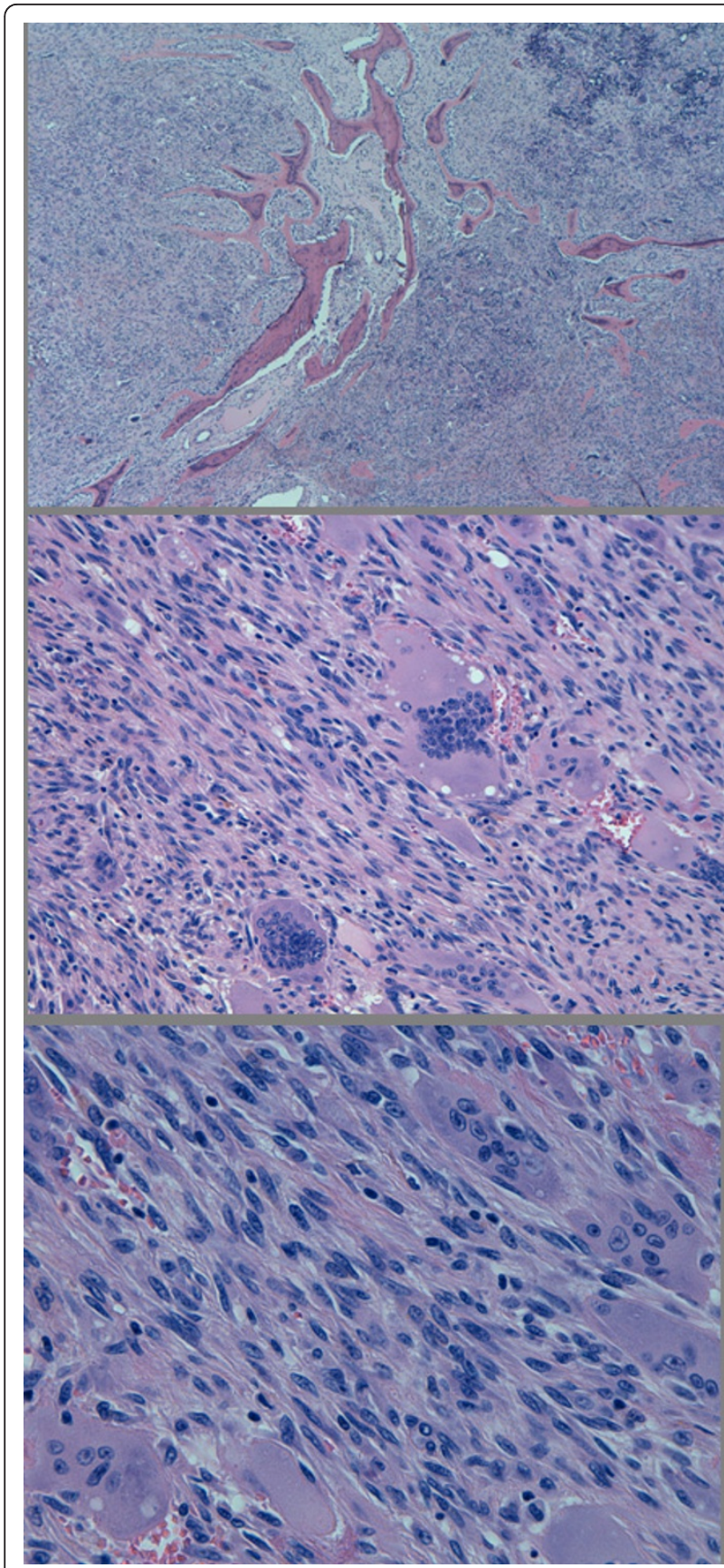

Figure 1 Histopathological analysis of the surgical specimens. Top: a solid mass with diffuse infiltration and destruction of bone tissue (hematoxilin and eosin (H\&E), original magnification 4X). Center: the solid mass is composed of numerous multinucleated giant cells in a background of middle-sized cells (H\&E, original magnification 20x). Bottom: at higher magnification, the background spindle-cell component is seen to be composed of mononuclear spindle-shaped or oval-shaped cells, with eosinophilic cytoplasm and oval nuclei without atypia (H\&E, original magnification 40x)
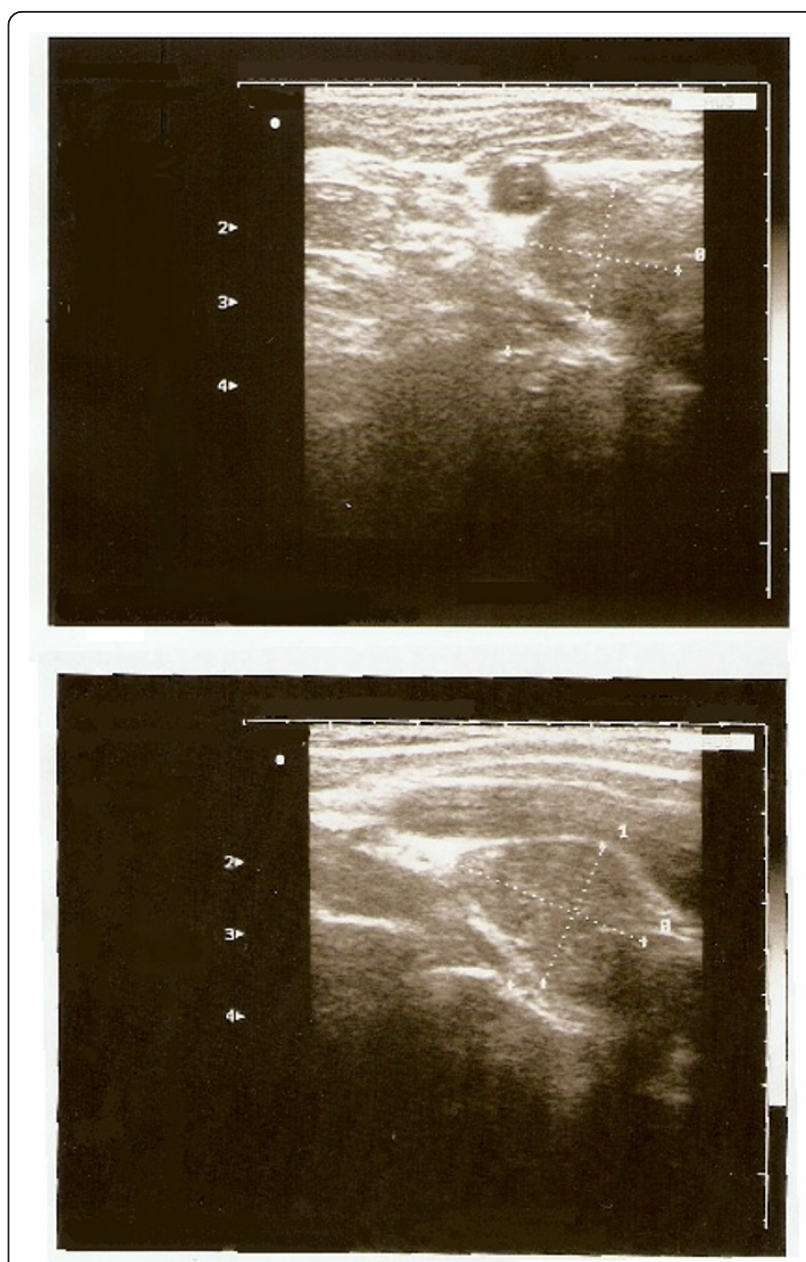

Figure 2 Neck ultrasonography images obtained about 21 months previously, demonstrating a solid cervical mass of 14 $\times 16 \times 27 \mathrm{~mm}$, with intra-lesional vascularization, under the right thyroid lobe. After fine-needle aspiration biopsy (FNAB), parathyroid hormone (PTH) evaluation on fine-needle washing was $550 \mathrm{pg} / \mathrm{mL}$; this value was higher than our institutional standard cut-off value of $132 \mathrm{pg} / \mathrm{mL}$ [30].

carcinomas [17] of the parathyroid glands. This particular manifestation of PHPT appears in advanced stages of the disease. In contrast with these previous reports, in our patient's case there was no evidence of advanced end-stage disease. Moreover, our patient was only 40 years of age and presented with only slight osteopenia without other symptoms or signs of malnutrition. However, she showed typical laboratory findings of PHPT.

Increased PTH levels induce the proliferation and differentiation of pluripotent bone-marrow cells into osteoblasts and induce the migration and differentiation of monocytes into osteoclasts; the increased number of the latter in the bone tissue $[3,6]$ causes bone resorption to 

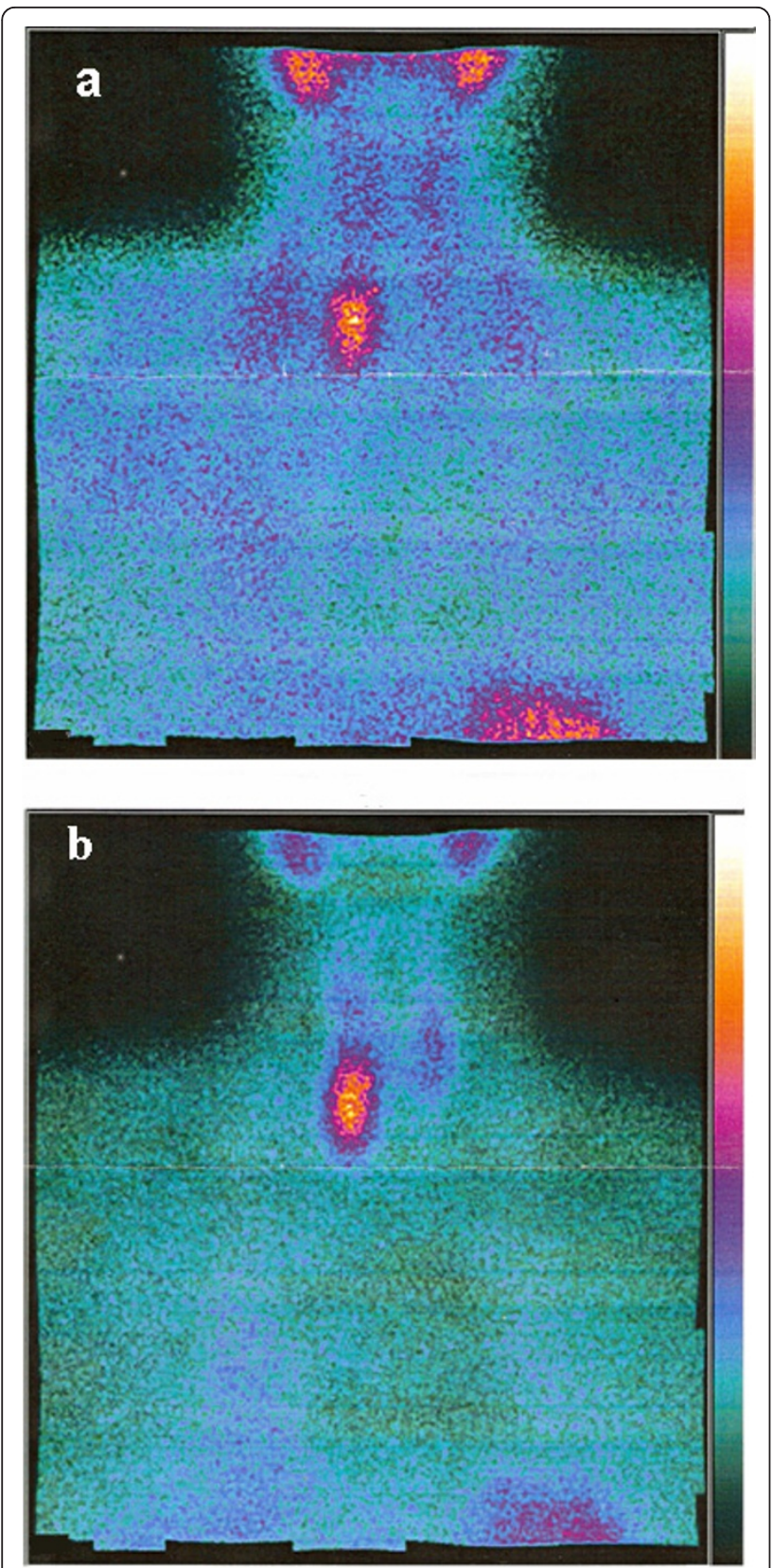

Figure 3 Cervical scintigraphy obtained at the baseline (A) and two hours after (B) $185 \mathrm{mBq}$ of ${ }^{99} \mathrm{~m}$ T-sestamibi injection about 22 months previously; accumulation of the isotope reflects the hyperfunctioning parathyroid adenoma.

predominate over the formation of new bone tissue. Brown tumor therefore involves a combination of osteoblastic and osteoclastic activity.

Brown tumors were first reported about two decades ago in $1.5 \%$ to $1.7 \%$ of patients with secondary hyperparathyroidism and in $3 \%$ of those with PHPT $[6,18]$.

Our patient's case of PHPT is probably sporadic, as the majority of parathyroid tumors are sporadic. Only
$5 \%$ are associated with hereditary endocrine tumor syndrome, which includes such diseases as MEN-1, MEN-2, familial benign hypocalciuric hypercalcemia and familial isolated PHPT.

These lesions may appear in any part of the skeleton and one or more bones may be involved. Lesions are generally located in areas of intense bone resorption [19].

Localized brown tumors are difficult to diagnose because they present clinically and radiologically as expansile multi-locular masses. The upper end of the tibia is the most common site of these lesions; unusual sites include the pelvic bone, mandible, ribs, femur and vertebral body.

In our patient, serum 25-hydroxyvitamin D $(25[\mathrm{OH}] \mathrm{D})$ was low, and it is well known that, in asymptomatic $\mathrm{PHPT}$, low 25[OH]D levels are associated with increased disease activity [20]. The tumors may cause pain and/or fractures. Symptoms depend on the size and location of the lesions. In other cases, lesions have been asymptomatic, the diagnosis following incidental radiological detection.

Histopathological analysis of the osseous lesion is needed in order to confirm the diagnosis of a brown tumor. As brown tumors exhibit no pathognomonic histological changes, it may be very difficult to distinguish a brown tumor from other giant-cell tumors, even on histological examination. In our patient, the histological findings suggested a giant-cell expanding bone lesion. It is important to point out that brown tumors are non-neoplastic lesions that are very similar to GCT; in the context of PHPT, they are considered reparative granulomas and do not have the malignant or neoplastic potential of true giant-cell lesions.

On X-ray imaging, brown tumors appear as lytic lesions with tortuous contours. Concurrent changes, such as osteopenia, a 'salt-and-pepper' bone appearance and subperiostal bone resorption, suggest OFC. Tomography shows an osseous mass and areas that appear cystic [21]. MRI may be better able to determine the presence of cysts. $\mathrm{On}^{99} \mathrm{~m}_{\mathrm{Tc}}$-sestamibi, isolated hypermetabolic lesions and the simultaneous hypercaptation of bone lesions and parathyroid adenomas have been described [22].

The main differential diagnosis is with GCT $[6,18]$, which is a highly vascular lesion. The radiological appearance and, even more so, the histology of GCT may closely mimic brown tumor, as in our patient. As it is very difficult to distinguish brown tumors from other giant-cell lesions histologically or radiologically, a definitive diagnosis is only possible on comparing the clinical manifestations and radiological and laboratory test results that differentiate the lesions. Thus, the clinical diagnosis is made in relation to PHPT $[7,10]$. 
Table 1 Some laboratory data and T scores data from dual-emission X-ray absorptiometry analysis performed before and after parathyroidectomy

\begin{tabular}{|c|c|c|c|c|c|c|}
\hline & Admission & $\begin{array}{l}\text { Before bone } \\
\text { tumor surgery }\end{array}$ & $\begin{array}{l}\text { After bone } \\
\text { tumor surgery }\end{array}$ & $\begin{array}{l}\text { Before } \\
\text { parathyroidectomy }\end{array}$ & $\begin{array}{l}\text { After } \\
\text { parathyroidectomy }\end{array}$ & $\begin{array}{l}1 \text { year post- } \\
\text { parathyroidectomy }\end{array}$ \\
\hline $\begin{array}{l}\mathrm{Ca}(\mathrm{mmol} / \mathrm{L}) \text {, normal value } \\
2.1 \text { to } 2.7\end{array}$ & 3.7 & 3.6 & 3.6 & 3.2 & 2.3 & 2.3 \\
\hline $\begin{array}{l}\mathrm{P}(\mathrm{mmol} / \mathrm{L}) \text {, normal value } \\
0.81 \text { to } 1.45\end{array}$ & 0.55 & 0.48 & 0.68 & 0.48 & - & 0.81 \\
\hline $\begin{array}{l}\text { ALP }(U / L) \text {, normal value } 98 \text { to } \\
280\end{array}$ & 347 & 501 & 423 & 224 & - & 192 \\
\hline $\begin{array}{l}\text { PTH (ng/L), normal value } 17 \\
\text { to } 73\end{array}$ & - & - & 712 & 873 & 88 & 80 \\
\hline $\begin{array}{l}\text { Creatinine }(\mu \mathrm{mol} / \mathrm{L}) \text {, normal } \\
\text { value } 45 \text { to } 120\end{array}$ & 70 & - & - & 70 & - & - \\
\hline $\begin{array}{l}25[\mathrm{OH}] \mathrm{D}(\mu \mathrm{g} / \mathrm{L}) \text {, normal value } \\
6 \text { to } 46\end{array}$ & - & - & - & 13 & 8.2 & 9.9 \\
\hline $\begin{array}{l}1,25(\mathrm{OH})_{2} \mathrm{D}(\mathrm{pmol} / \mathrm{L}) \text {, normal } \\
\text { value } 48 \text { to } 110\end{array}$ & - & - & - & 212.3 & 70.7 & 101.7 \\
\hline $\begin{array}{l}\text { Osteocalcin }(\mu \mathrm{g} / \mathrm{L}) \text {, normal } \\
\text { value } 6.5 \text { to } 42.3\end{array}$ & - & - & - & 60.3 & - & 14.1 \\
\hline T-score, L2 to L4 & - & - & - & -2.48 & -1.63 & -1.25 \\
\hline T-score, femoral & - & - & - & -1.91 & -1.29 & -0.99 \\
\hline
\end{tabular}

1,25(OH) 2 D, 1,25-dihydroxyvitamin $\mathrm{D}_{3} ; 25[\mathrm{OH}] \mathrm{D}, 25$-hydroxyvitamin $\mathrm{D} ; \mathrm{ALP}$, alkaline phosphatase; PTH, parathyroid hormone.

The first step in the management of brown tumor is to treat PHPT, which may be performed by means of parathyroidectomy. The effect of parathyroidectomy on brown tumors depends on their composition [23]. After treatment of the underlying metabolic disorder, the regression or complete remission of brown tumors has been well documented [24] in primary and secondary hyperparathyroidism. Patient age appears to be an important factor in predicting the time required for brown tumors to regress. Several authors consider parathyroidectomy the only correct therapy [24]. However, several cases have been reported of brown tumors that grew after parathyroidectomy or normalization of PTH levels [25]. In these cases, resection of the brown tumor should be the treatment of choice. Some authors [26] believe that bone lesions reappear spontaneously following removal of the diseased parathyroid gland; others [27] recommend initial treatment with systemic corticosteroids to reduce tumor size, followed by surgical removal of the residual lesion. Surgical resection and decompression of brown tumors should be considered if the patient is symptomatic [28]. In cases in which lesions persist for more than six months, or there is disruption of the function of the affected organ, or growth despite adequate metabolic control, some authors [25] have recommended tumor curettage and associated enucleation. Finally, vitamin D improves serum PTH levels, and medical treatment based on high doses of vitamin D is effective in many cases of brown tumor [29].

\section{Conclusions}

In summary, we report the case of a 40-year-old woman with the association of brown tumor and a single parathyroid adenoma, in whom a bone neoplasm was first suspected. The correct diagnosis was reached only later, despite the many clinical manifestations. Radiograph studies showed a combination of typical changes. This case highlights the many similarities between GCT and brown tumor.

\section{Consent}

Written informed consent was obtained from the patient for publication of this case report and any accompanying images. A copy of the written consent is available for review by the Editor-in-Chief of this journal.

Author details

'Department of Internal Medicine, University of Genoa, Viale Benedetto XV, 6-16132, Genoa, Italy. ${ }^{2}$ Department of Pathology, National Institute for Cancer Research, Genoa, Italy.

\section{Authors' contributions}

LV analyzed and interpreted the data from our patient regarding endocrinological disease; MD and SO were contributors to writing the manuscript; MM and MGU performed the histological examination of bone samples; MGI was a major contributor to writing the manuscript. All authors read and approved the final manuscript.

\section{Competing interests}

The authors declare that they have no competing interests.

Received: 4 July 2011 Accepted: 28 December 2011

Published: 28 December 2011 


\section{References}

1. Youanes NA, Shafagoij Y, Khatib F, Ababneh M: Laboratory screening for hyperparathyroidism. Clin Chim Acta 2005, 353:1-12.

2. Kearns AE, Thompson GB: Medical and surgical management of hyperparathyroidism. Mayo Clin Proc 2002, 77:87-89.

3. Campuzano-Zuluaga G, Velasco-Perez W, Marian-Zuluaga Jl: A 60-year-old man with chronic renal failure and a costal mass: a case report and review of the literature. J Med Case Rep 2009, 3:7285.

4. Sywak MS, Knowlton ST, Pasieka JL, Parsons LL, Jones J: Do the National Institutes of Health Consensus Guidelines for Parathyroidectomy predict symptom severity and surgical outcome in patients with primary hyperparathyroidism? Surgery 2002, 132:1013-1019.

5. Rubin MR, Livolsi VA, Bandiera F, Caldas G, Bilezikian JP: Tc99 m-sestamibi uptake in osteitis fibrosa cystica simulating metastatic bone disease. $J$ Clin Endocrin Metab 2001, 86:5138-5141.

6. Takeshita T, Tanaka H, Harasawa A, Kaminaga T, Imamura T, Furui S: Brown tumor of the sphenoid sinus in a patient with secondary hyperparathyroidism: CT and MR imaging findings. Rad Med 2004, 22:265-268.

7. Keyser JS, Postma GN: Brown tumor of the mandible. Am J Otolaryngol 1996, 17:407-409.

8. Fitzgerald P: Endocrinology. In Current Medical Diagnosis \& Treatment.. 39 edition. Edited by: Tierney LM, McPhee Sj, Papadakis MA. Stamford, CT: Appleton 2000:1118-1121.

9. Rosemberg EH, Guralnick WC: Hyperparathyroidism: a review of 220 proved cases, with special emphasis on findings in the jaws. Oral Surg Oral Med Oral Pathol Oral Radiol Endod 1962, 15:84-94.

10. Som PM, Lawson W, Cohen BA: Giant cell lesions of the facial bones. Radiology 1983, 147:129-132.

11. Proimos E, Chimona T, Tamiolakis D, Tzanakakis MG, Papadakis CE: Brown tumor of the maxillary sinus in a patient with primary hyperparathyroidism: a case report. J Med Case Rep 2009, 3:7495.

12. Balke M, Campanacci L, Gebert C, Picci P, Gibbons M, Taylor R, Hogendoorn P, Kroep J, Wass J, Athanasou N: Bisphosphonate treatment of aggressive primary, reccurent and metastatic giant cell tumor of bone. BMC Cancer 2010, 10:462.

13. Lau YS, Sabokbar A, Gibbons CL, Giele H, Athanasou N: Phenotypic and molecular studies on giant cell tumours of bone and soft tissues. Hum Pathol 2005, 36:945-954.

14. Bertoni F, Bacchini P, Staals EL: Malignancy in giant cell tumor of bone. Cancer 2003, 97:2520-2529.

15. Kar DK, Gupta SK, Agarwal A, Mishra SK: Brown tumor of the palata and mandible in association with primary hyperparathyroidism. J Oral Maxillofac Surg 2001, 59:1352-1354.

16. Fernandez-Sanroman J, Anton-Badiola IM, Costas-Lopez A: Brown tumor of the mandible as first manifestation of primary hyperparathyroidism: diagnosis and treatment. Med Oral Patol Oral Cir Bucal 2005, 10:169-170.

17. Pahlava PS, Severin MC: Parathyroid carcinoma: a rare case with mandibular brown tumor. Wien Klin Wochenschr 2006, 118:175-179.

18. Azria A, Beaudreuil J, Juquel JP, Quillard A, Bardin T: Brown tumor of the spine revealing secondary hyperparathyroidism. Report of a case. Joint Bone Spine 2000, 67:230-233.

19. Pinto MC, Sass SM, Sampaio CP, Campos DS: Brown tumor in a patient with hyperparathyroidism secondary to chronic renal failure. Braz $J$ Otorhinolaryngol 2010, 76:404.

20. Bilezikian JP, Brandi ML, Rubin M, Silverberg SJ: Primary hyperparathyroidism: new concepts in clinical, densitometric and biochemical features. I Internal Med 2005, 257:6-17.

21. Takeshita T, Takeshita K, Abe S, Takami H, Imamura T, Furui S: Brown tumor with fluid-fluid levels in a patient with primary hyperparathyroidism: radiological finding. Radiat Med 2006, 24:631-634.

22. Yapar AF, Aydin M, Reyhan M, Bal N, Yapar Z, Yologlu NA: Simultaneous visualization of a mandibular brown tumor with a large parathyroid adenoma on Tc-99 m MIBI imaging. Clin Nucl Med 2005, 30:433-435.

23. Franco M, Bendini JC, Albano L, Barrillon D, Cassuto E, Bracco J: Radiographic follow-up of a phalangeal brown tumor. Joint Bone Spine 2002, 69:506-510.

24. Bereket A, Casur Y, Firat P, Yordam N: Brown tumor as a complication of secondary hyperparathyroidism severe long-lasting vitamin $D$ deficient rickets. Eur J Pediatr 2000, 159:70-73.
25. Yamazaki H, Ota Y, Aoki T, Karakida K: Brown tumor of the maxilla and mandible. Progressive mandibular brown tumor after removal of parathyroid adenoma. J Oral Maxillofac Surg 2003, 61:719-722.

26. Scott SN, Graham SM, Sato Y, Robinson RA: Brown tumor of the palate in a patient with primary hyperparathyroidism. Ann Otol Rhinol Laryngol 1999, 108:91-94.

27. Martinez-Gravidia EM, Bagan JV, Milian-Masanet MA, Lloria de Miguel E, Pérez-Vallés A: Highly aggressive brown tumor of the maxilla as first manifestation of primary hyperparathyroidis. Int I Oral Maxillofac Surg 2000, 29:447-449.

28. Lessa MM: Brown tumor of the facial bones: case report and literature review. Ear Nose Throat I 2005, 84:42-44.

29. Francisco AL: Secondary hyperparathyroidism: review of the disease and its treatment. Clin Ther 2004, 26:1976.

30. Giusti M, Dolcino M, Vera L, Ghiara C, Massaro F, Fazzuoli L, Ferone D, Mussap M, Miunto F: Institutional experience of PHT evaluation on fineneedle washing after aspiration biopsy to locate hyperfunctioning parathyroid tissue. J Zhejiang Univ Sci B 2009, 10:323-330.

doi:10.1186/1752-1947-5-596

Cite this article as: Vera et al:: Primary hyperparathyroidism diagnosed after surgical ablation of a costal mass mistaken for giant-cell bone tumor: a case report. Journal of Medical Case Reports 2011 5:596.

\section{Submit your next manuscript to BioMed Central and take full advantage of:}

- Convenient online submission

- Thorough peer review

- No space constraints or color figure charges

- Immediate publication on acceptance

- Inclusion in PubMed, CAS, Scopus and Google Scholar

- Research which is freely available for redistribution

Submit your manuscript at www.biomedcentral.com/submit
Biomed Central 